\title{
ResearchOnline@JCU
}

This is the author-created version of the following work:

Drovandi, Aaron, Salem, Saad, Barker, Daniel, Booth, Debbie, and Kairuz, Therese (2019) Human biomarker exposure from cigarettes versus novel heat-notburn devices: a systematic review and meta-analysis. Nicotine and Tobacco Research, . (In Press)

Access to this file is available from: https://researchonline.jcu.edu.au/60757/

(C) The Author(s) 2019. Published by Oxford University Press on behalf of the Society for Research on Nicotine and Tobacco. All rights reserved. The Accepted Manuscript of this publication will be available Open Access from ResearchOnline@JCU from 24 October 2020.

Please refer to the original source for the final version of this work: https://doi.org/10.1093/ntr/ntz200 


\section{Human Biomarker Exposure from Cigarettes versus Novel Heat-Not-Burn \\ Devices: A Systematic Review and Meta-Analysis}

Aaron Drovandi ${ }^{1 *} \mathrm{PhD}$, Saad Salem ${ }^{2} \mathrm{PhD}$, Daniel Barker ${ }^{3} \mathrm{PhD}$, Debbie Booth ${ }^{4}$, Therese Kairuz $^{2} \mathrm{PhD}$

* Corresponding Author

${ }^{1}$ College of Medicine and Dentistry, James Cook University, Townsville, Australia

${ }^{2}$ School of Biomedical Sciences and Pharmacy, University of Newcastle, Newcastle, Australia

${ }^{3}$ School of Medicine and Public Health, University of Newcastle, Newcastle, Australia

${ }^{4}$ University Library, University of Newcastle, Newcastle, Australia

Corresponding Author:

Aaron Drovandi

Building 47 (Pharmacy \& Medical Research), 1 James Cook Drive

James Cook University, Townsville, Australia, 4814

Email: aaron.drovandi@jcu.edu.au

Phone: +61 747813437

Fax: $\quad+61747258108$ 


\section{ABSTRACT}

Introduction: Novel tobacco products require independent research to assess their safety. This study assessed the current literature for trials comparing levels of biomarkers of exposure (BoE) between conventional cigarettes and heat-not-burn (HNB) devices.

Methods: Ten databases were searched using terms including: 'heat not burn', 'iqos', 'teeps', 'mrtp', 'tobacco heating', and 'glo', between 1st January 2010 and 13th August 2019. Randomised controlled trials assessing comparative BoE levels in humans using either conventional cigarettes or novel $\mathrm{HNB}$ devices were eligible. BoE were tabulated, and differences between the intervention and control groups analysed and combined using a random effects meta-analysis.

Results: Ten non-blinded, randomised controlled trials were eligible, involving a total of 1,766 participants. Studies regularly reported on $12 \mathrm{BoE}$ (including nicotine). HNB devices assessed included the 'IQOS' and 'glo' devices, and 'precursor' (being developed) HNB devices. In comparison to conventional cigarettes, all 12 BoEs assessed were significantly lower for participants assigned to a HNB device. In comparison to smoking abstinence, HNB devices were statistically equivalent for eight BoEs and significantly elevated for four BoEs.

Conclusions: This review found that the potential for harm to humans is reduced when using HNB devices compared to conventional cigarettes, as indicated by significant reductions in BoE levels. Whilst these results support tobacco manufacturer claims of improved safety, the small number of studies included, limited range of BoE assessed, and involvement of the tobacco industry necessitate further independent research to confirm the HNB devices as being a safer alternative to conventional cigarettes. 


\section{IMPLICATIONS}

This study supports claims made by tobacco manufacturers on the improved safety of heat-notburn tobacco devices in comparison to conventional cigarettes. These novel devices lead to reduced exposure to key biomarkers, which are linked to the health consequences attributed to tobacco use. This has strong implications for international public health as well as further research and policy development relating to the safety aspects and legalities of novel tobacco products.

\section{ABBREVIATIONS}

\begin{tabular}{|c|c|}
\hline 1-OHP & 1-hydroxypyrene \\
\hline $2-\mathrm{AN}$ & 2-aminoaphthalene \\
\hline 3-HРMA & 3-hydroxypropylmercaptapuric acid \\
\hline 4-ABP & 4-aminobiphenyl \\
\hline BAT & British American Tobacco \\
\hline BoE & Biomarker of Exposure \\
\hline $\mathrm{CC}$ & Conventional Cigarette \\
\hline CEMA & 2-cyanoethylmercapturic acid \\
\hline CI & Confidence Interval \\
\hline $\mathrm{COHb}$ & Carboxyhemoglobin \\
\hline HNB & Heat-Not-Burn \\
\hline HPHC & Harmful and Potentially Harmful Constituents \\
\hline JBI & Joanna Briggs Institute \\
\hline MHBMA & Monohydroxybutenyl-mercapturic Acid \\
\hline NNN & N-nitrosonornicotine \\
\hline NNAL & 4-(methylnitrosamino)-1-(3-pyridyl)-1-butanol \\
\hline o-tol & o-toluidine \\
\hline IQOS & I Quit Original Smoking \\
\hline PMI & Philip Morris International \\
\hline PRISMA & Preferred Reporting Items for Systematic Reviews and Meta-Analyses \\
\hline $\mathrm{RCT}$ & Randomised Controlled Trial \\
\hline S-PMA & S-phenylmercapturic acid \\
\hline $\mathrm{SD}$ & Standard Deviation \\
\hline TNeq & Total Nicotine equivalents \\
\hline
\end{tabular}




\section{INTRODUCTION}

Tobacco use remains a leading preventable cause of morbidity and mortality and is linked to a growing array of health consequences, including lung cancer, chronic obstructive pulmonary disorder, and cardiovascular diseases. ${ }^{1,2}$ An individual's risk of tobacco-attributable diseases is influenced by both their genetic predisposition and lifetime cumulative exposure to harmful tobacco product constituents, including through exposure to second and third-hand smoke., Conventional cigarettes remain a primary method for the inhalation of tobacco smoke, which contain thousands of chemical constituents, many of which are known carcinogens. As global tobacco use is predicted to reach 1.5 billion smokers by $2050,{ }^{5}$ the World Health Organization and other public health stakeholders have attempted to manage the tobacco epidemic through recommending comprehensive tobacco control policies. This includes prohibiting advertising, regulating tobacco product appearance, and implementing tax increases. ${ }^{6}$ However, tobacco manufacturers continue their attempts to circumvent these regulations, to ensure maintenance of the smoking culture, and recruitment of the 'next generation' of smokers. ${ }^{7-10}$

One such method for attracting and retaining smokers is the development and marketing of 'heat-not-burn' (HNB) devices, which can resemble either electronic or conventional cigarettes in appearance, and are promoted as 'reduced-risk' tobacco products. ${ }^{11}$ Unlike electronic cigarettes which utilise a nicotine-containing liquid or conventional cigarettes which achieve combustion by heating to at least $600^{\circ} \mathrm{C}$, these devices heat either a nicotine-free liquid which passes through tobacco leaf, or heat processed tobacco leaf to less than $350^{\circ} \mathrm{C}$. It is proposed that HNB devices are less harmful to human health than conventional cigarettes through reduced exposure to carcinogens and other toxic constituents. ${ }^{11,12}$ The earliest models of these HNB devices such as 'Premier', 'Eclipse' and 'Accord' were developed in the 1980s and 1990s. However, several issues were cited by smokers, including difficult operation and poor taste, which led to most of the early HNB devices being discontinued by the mid-2000s. ${ }^{13,14}$ 
Following the poor uptake of these earlier models, emerging HNB devices include the 'I Quit Original Smoking' (IQOS; Philip Morris International [PMI]) and 'glo' (British American Tobacco [BAT]), which were first made available in Japan and Italy, though have rapidly spread to other countries. ${ }^{15}$

If HNB devices are less harmful than conventional cigarettes, they could represent a method for harm reduction, by allowing individuals to continue smoking behaviours and satisfying their nicotine addiction, whilst causing less harm to themselves and others. Assessing toxicant exposure and estimating health risks associated with tobacco products can be achieved through determining the levels of biomarkers of exposure $(\mathrm{BoE})$. These are measures of exposure to 'harmful and potentially harmful constituents' (HPHC) within tobacco products. The Institute of Medicine of the US Academy of Science defines a BoE as "a tobacco constituent or metabolite that is measured in a biological fluid or tissue that has the potential to interact with a biological macromolecule; sometimes considered a measure of internal dose". ${ }^{16}$ BoE can therefore provide a more accurate assessment of health risk compared to the quantity of exposure (e.g. cigarettes per day), through utilising a range of variables (tobacco and diseaserelated) which allows comparison of the relative harms of different tobacco products. ${ }^{16}$

The concept of a risk continuum by McNeill and Munafò (2013) places conventional cigarettes at the high-risk end, nicotine replacement therapy at the low-risk end and HNB products at a to-be-determined point in between. ${ }^{17}$ Assessing the absolute risk of these devices is ongoing, with independent research required to guide relevant legislation and policy development. A recent (2018) independent review assessing the emissions, safety, and epidemiology of HNB products found that "switching from smoking cigarettes to using HNB significantly reduces but does not eliminate exposure to HPHC'. ${ }^{18}$ However, contradictory data released from PMI on their own IQOS device indicated there may be no significant difference in harm compared to conventional cigarettes. ${ }^{19}$ Due to the debate on comparative safety between HNB products and 
conventional cigarettes, and increasing public interest in these products, ${ }^{20}$ we conducted a systematic review and meta-analysis to explore the safety profiles of HNB devices compared to conventional cigarettes. The underlying aim for this review was to evaluate comparative BoE levels resulting from use of either conventional cigarettes versus novel HNB devices.

\section{METHODS}

This systematic review is reported according to the recommendations of the PRISMA (Preferred Reporting Items for Systematic Reviews and Meta-Analyses) guidelines. ${ }^{21}$

\section{Search strategy and study eligibility}

A systematic search strategy was used to identify original studies published in English between $1^{\text {st }}$ January 2010 and $13^{\text {th }}$ August 2019. The date limit was set to ensure inclusion of articles relating to emerging HNB devices, such as 'THS2.2' (IQOS), and 'THP1.0' (glo), whilst excluding outdated precursor HNB devices such as 'Eclipse', 'Accord' and 'Premier'. Ten databases were searched: CINAHL, Cochrane Library, EBSCO MegaFile Premier, EMBASE, Global Health, Medline, ProQuest, PsycINFO, Scopus, and Web of Science. General search terms included 'tobacco heating', 'heat not burn', 'HNB', 'modified risk tobacco product', and 'mrtp', and device-specific terms such as 'iqos', 'teeps', and 'glo'. A full search strategy detailing the search terms, dates, and databases used is available in Supplementary Appendix 1. Citation and reference lists were scanned to identify additional eligible studies.

Studies eligible for inclusion were those that investigated the safety of HNB products in humans through assessing BoE levels compared to conventional cigarettes. Studies that investigated $\mathrm{BoE}$ or other safety data on mice, rats, or in-vitro human tissue samples were ineligible, as we intended to collect BoE data that results directly from human exposure. Studies that assessed the safety of electronic cigarettes, or non-safety-related aspects of HNB products, such as availability or public opinions were also excluded, as were expert opinions 
and conference abstracts. Titles of potentially eligible studies were initially scanned by a single author (AD), with the assessment of the remaining studies for eligibility being performed by three authors (AD, SS, TK). Abstracts were read by these authors, who independently crosschecked each other's lists of potentially eligible studies. Full-texts were then read to assess for final eligibility, with disagreements resolved by consensus.

\section{Data extraction and quality appraisal}

Two authors (AD and $\mathrm{DB})$ were responsible for data extraction. Data items extracted were: author affiliations, source(s) of funding, year of publication, study type, country of participant recruitment, participant demographics (including smoking habits), intervention and control groups employed, participant numbers assigned to each group, duration of exposure to interventions, puffing topography, and biomarkers measured. The primary outcome of interest from these studies included differences in BoE levels after assignment to the intervention or control groups, and comparative BoE differences between these groups.

Study quality was assessed by two authors (SS and TK) and checked by a third author (AD), with disagreements resolved by consensus. The Joanna Briggs Institute (JBI) critical appraisal checklist for randomised controlled trials was used to assess study quality. ${ }^{22}$ This validated 13item checklist assesses study quality based on the method of randomisation used, similarity in participant characteristics between groups, level of blinding amongst the involved parties (including participants, those delivering treatment, and assessors), appropriateness of statistical analysis, and sources of selection and analytical bias. Due to the strong links between the eligible studies and tobacco manufacturers (including author employment and the provision of funding), the authors of this review were careful in assessing the sources and significance of bias in eligible articles. This included assessing the clarity of the descriptions provided relating to the equal treatment of participant groups, the method of randomisation, outcome measurements, and appropriateness of trial design. Studies were considered as high quality if 
they sufficiently addressed 11 of the 13 JBI checklist items, moderate quality if they addressed between 7 and 10 of the criteria, and low quality if they addressed 6 or fewer of the criteria.

\section{Data synthesis and analysis}

Each BoE was assessed individually and compared between the HNB, conventional cigarettes (CC) and abstinence (Abs) groups. Studies captured within this review all used a pre-post design with one or two control groups (CC and/or Abs). Standardised effect sizes $(d)$ were therefore calculated according to the method recommended by Carlson and Schmidt, ${ }^{23}$

$$
d=\frac{\left(T_{\text {post }}-T_{\text {pre }}\right)-\left(C_{\text {post }}-C_{\text {pre }}\right)}{S D_{\text {pre }}}
$$

where $T_{\text {post }}$ and $C_{\text {post }}$ are the post-intervention means of the outcome in treatment and comparison groups respectively, $T_{\text {pre }}$ and $C_{\text {pre }}$ are the corresponding pre-intervention means, and $\mathrm{SD}_{\text {pre }}$ is the pooled standard deviation of the two groups at the pre-intervention time period. As $d$ is a biased estimator with small sample sizes, we used the correction factor suggested by Hedges, ${ }^{24}$ where $n_{i}$ is the total sample size for the $i$ th comparison (i.e. $n_{i}=n_{T}+n_{C}$ ):

$$
J=1-\frac{3}{4 \times\left(n_{i}-1\right)-1}
$$

The reported effect sizes (ES) are the product $d \times \mathrm{J}$, with variance given by the equation below, where $\rho$ is the correlation between the pre- and post-measurements within a group: ${ }^{25}$

$$
\operatorname{Var}(E S)=2 J^{2}(1-\rho)\left(\frac{n_{T}+n_{C}}{n_{T} n_{C}}\right)\left(\frac{n_{T}+n_{C}-2}{n_{T}+n_{C}-4}\right)\left(1+\frac{d^{2}}{2(1-\rho)\left(\frac{n_{T}+n_{C}}{n_{T} n_{C}}\right)}\right)-d^{2}
$$

For trials where the means and standard deviations of the change (defined as post - pre) were available, this correlation was estimated for each group separately using:

$$
\rho=\frac{S D_{\text {pre }}{ }^{2}+S D_{\text {post }}^{2}-S D_{\text {diff }}{ }^{2}}{2 \times S D_{\text {pre }} \times S D_{\text {post }}}
$$


This was then averaged as appropriate for the $i$ th comparison. However, in many instances data on change was not available and we therefore imputed the average pre-post correlation from those trials which did report change. Sensitivity analyses were also conducted assuming $\rho=$ 0.1 and $\rho=0.9$ for all studies. After a standardised effect size and corresponding confidence interval was calculated for each study using the above, the overall effect size estimate was combined using a random effects model according to the method of DerSimonian \& Laird. ${ }^{26}$

\section{RESULTS}

\section{Search results and study characteristics}

The search strategy yielded 4,123 results, which after de-duplication from the multiple databases resulted in 1,397 unique studies. Initial title screening by AD excluded 813 studies, with the remaining 584 studies assessed for eligibility by three authors (AD, SS, TK). Abstract screening excluded a further 549 studies, leaving 35 for full-text review. Full-text review excluded a further 25 , leaving 10 eligible studies included in this systematic review and metaanalysis. Figure 1 details the results of the systematic search.

Across the 10 studies, $21 \mathrm{BoE}$ (including nicotine) were reported. Biomarkers were collected throughout the intervention period via 24-hour urine samples, and daily blood samples in the six studies that had a confinement period, and at set points in those with an ambulatory period. To limit the number of biomarkers being assessed and to ensure meaningful outcomes through a sufficient quantity of data, only biomarkers that were reported in at least eight of the ten eligible studies were analysed. Twelve biomarkers met this criteria: 1-hydroxypyrene (1-OHP),

2-aminoaphthalene (2-AN), 3-cyanoethylmercapturic acid (CEMA), 3hydroxypropylmercaptauric acid (3-HPMA), 4-aminobiphenyl (4-ABP), 4(methylnitrosamino)-1-(3-pyridyl)-1-butanol (NNAL), carboxyhemoglobin $\quad(\mathrm{COHb})$, monohydroxybutenyl-mercapturic acid (MHBMA), n-nitrosonornicotine (NNN), o-toluidine 
(0-tol), s-phenylmercapturic acid (S-PMA), and total nicotine equivalents (TNeq).

Supplementary Appendix 2 lists the 21 BoEs evaluated throughout the studies, their attributed HPHCs, and the $12 \mathrm{BoE}$ that were eligible and assessed in this review (bolded).

A total of 1,766 participants were involved in the 10 studies, which were conducted in Japan, Poland, or the USA. Table 1 details study characteristics and participant demographics. Most studies utilised a randomised controlled trial (RCT) design, except for one semi-RCT design. ${ }^{27}$ Common participant exclusion criteria were: inadequate contraception, pregnant or breastfeeding, recent blood donation, current acute illness, recent non-cigarette tobacco use, planned to quit smoking within 12 months, or had abnormal laboratory tests (physical, medical, ECG, lung function, or laboratory panel). All studies had most or all of the authors employed by a tobacco manufacturer, and all studies were funded by these manufacturers. After baseline measurements, participants were allocated to continue smoking conventional cigarettes, exclusively use a HNB device, or be completely abstinent from nicotine products.

Conventional cigarettes used were the smokers' usual brand, except for two studies that provided cigarettes. ${ }^{27,32} \mathrm{HNB}$ devices included the commercially available 'glo' and 'IQOS', as well as 'precursor' products, which includes devices still under development, and earlier device models which have been refined and are now commercially available. Nicotine quantity in the HNB devices ranged from $0.3 \mathrm{mg}$ to $1.21 \mathrm{mg}$ per stick/capsule. These devices all include a rechargeable battery-powered heating element and insert-able capsule or stick which contains processed tobacco leaf. Some also contain a nicotine-free liquid, which is heated (instead of the tobacco leaf) into a vapour which passes through the tobacco, drawing out the nicotine and flavours. After baseline measurements and allocation, the intervention period ran for 5 days in confinement in six studies, ${ }^{28-32,34} 28$ days in a residential setting in one study, ${ }^{27} 5$ days in confinement followed by 85 days ambulatory in two studies study, ${ }^{33,35}$ and a 6-month ambulatory period in one study. ${ }^{36}$ For consistency across the studies, those that collected data 
both during confinement and in an ambulatory setting only had their confinement data analysed. Confinement involved physical restriction to the clinic for the duration of the intervention period, and supervised smoking only in smoking rooms during approved hours (6:30am to 11:00pm in most studies). HNB sticks/capsules and conventional cigarettes were provided one at a time upon participant request, with puffing topography (number of puffs, total puff volume, and puff duration) recorded throughout the confinement period in most of the studies..$^{27-31,33,34}$

\section{Quality Appraisal}

The JBI quality appraisal checklist found all ten studies as being of moderate quality, scoring 8 or 9 out of 13 . Four of the checklist items were commonly unmet by these studies, due to study design and being unable to blind participants or researchers (checklist items 2, 4, 5, and 6). This lack of blinding was due to the obvious and unavoidable differences in the interventions used between the different arms of these studies (conventional cigarette, HNB, or abstinence). A lack of clarity on the method of randomisation used (checklist item 1) was a further issue with some of the studies. An additional consideration relating to reporting bias, is that all ten studies had one or more of the authors employed by PMI, BAT, or Japan Tobacco Inc., with these companies also funding the research. Due to the small number of studies available and the unavoidable issues arising from trial design (relating to blinding), their inclusion in the analysis was necessary.

\section{Product use and biomarkers of exposure (BoE)}

Biomarker data were extracted from the full analysis set for most studies, except for two that used the per protocol set. ${ }^{33,35}$ Total daily use of HNB and conventional cigarette use was unrestricted in all but two studies, one which restricted both HNB and conventional cigarette use to $125 \%$ of usual daily cigarette consumption, ${ }^{32}$ and one which restricted conventional cigarette use to within $10 \%$ of usual cigarette consumption and HNB to 10 capsules per day ${ }^{34}$. 
In six unrestricted-use studies, the total number of HNB capsules/sticks used were generally comparable to the number of conventional cigarettes. However, total puff volume, number of puffs, and puff duration were increased for HNB devices compared to conventional cigarettes in four of these studies, ${ }^{27,28,30,31}$ and comparable in the remaining two studies. ${ }^{29,33}$ In the four studies with different puffing behaviours, total puff volume increased by between $5-27 \%$, number of puffs by $19-40 \%$, and puff duration by approximately $33 \% . .^{27,28,30,31}$ In the study which strictly limited consumption of conventional cigarettes (within $10 \%$ of normal use), total puff volume increased by nearly $200 \%, 30 \%$ increased puff duration, and $50 \%$ increased puff number for HNB participants. ${ }^{34}$

Despite the increases in HNB use in these studies, the levels of all 12 BoEs analysed in this meta-analysis were significantly lower in the HNB participants compared to those assigned to conventional cigarettes. Table 2 outlines the effect sizes of the $12 \mathrm{BoE}$ for the comparisons between the intervention and control groups, in descending order of effect size for HNB versus conventional cigarettes. Figure 2 illustrates (via forest plot) these effect sizes for each BoE, with the full set of 24 forest plots available in Supplementary Appendix 3. The most significant reductions between these two intervention groups were seen for 2-aminoaphthalene (2-AN), carboxyhemoglobin $\quad(\mathrm{COHb}), \quad 4$-aminobiphenyl $\quad(4-\mathrm{ABP}), \quad$ and $\quad 4-$ cyanoethylmercapturic acid (CEMA), all with negative effect sizes (standard deviations) of 1.2 or greater. Total nicotine equivalent (TNeq) exposure was the BoE least different between the two groups. In comparison to the abstinence group, the levels of 8 of 12 BoEs for HNB participants were not statistically different, whereas the BoEs 3-hydroxypropylmercaptauric acid (3-HPMA), N-nitrosonornicotine (NNN), 4-(methylnitrosamino)-1-(3-pyridyl)-1-butanol (NNAL), and TNeq were significantly higher in the HNB participants. TNeq had the greatest difference between the two groups, with a positive effect size of 1.91, whereas 3-HPMA, NNN, and NNAL had positive effect sizes of less than 0.25 . 


\section{DISCUSSION}

Potential modified risk tobacco products such as the 'IQOS' and 'glo' HNB devices have been developed by tobacco manufacturers in response to the growing dissent for conventional cigarettes. Manufacturers claim these devices provide an alternative source of nicotine with significantly reduced risk to users. This study aimed to evaluate these claims relating to the relative safety of HNB products compared to conventional cigarettes. The analyses conducted in this study support these claims, with the levels of all 12 BoEs evaluated being significantly lower in the HNB participants compared to the conventional cigarette participants. These reductions were apparent even with changes in puffing topography, including increased puff volume, puff duration, and number of puffs in those assigned to HNB devices compared to conventional cigarettes. In addition, levels of 8 of the 12 BoEs in HNB participants were not significantly different to smoking abstinence, indicating that although they may have improved safety over conventional cigarettes, the complete safety of HNB devices cannot be assured.

As described by Murphy et al (2017), arbitrary placement on the risk continuum can be rectified by supporting science that allows accurate placement and comparison of the relative safety of the various tobacco products available. ${ }^{38}$ It is therefore necessary to distinguish different potential modified risk tobacco products along this continuum, such as e-cigarettes and HNB devices, as well as the differences between individual HNB devices. ${ }^{17,38}$ A recent review by Simonavicius et al (2018) assessed HNB emissions, as well as BoEs from many of the RCTs analysed in the current study stated, "evidence on HNB second-hand emissions suggested that $H N B$ exposes users and bystanders to substantially lower but measurable levels of particulate matter and $H P H C$ '. ${ }^{18}$ The authors also described differences in potential harm between individual HNB devices, with the aerosol of IQOS containing the highest proportional levels of nicotine and HPHCs, followed by glo, and then the iFuse device. ${ }^{18}$ These findings indicate that safety cannot be assured for HNB devices, neither for the smoker nor close contacts, and 
that individual HNB devices may also have different relative levels of safety. Similar to the findings of the current study, Simonavicius and colleagues also noted that HNB participants utilised compensatory puffing techniques, which may have resulted from lower nicotine exposure per puff with HNB devices. ${ }^{18}$ Furthermore, the potential public health benefits of HNB devices may be marred by dual use of these devices with conventional cigarettes, which has been the case to some extent for electronic cigarettes. ${ }^{39}$ Dual use would substantially reduce the health benefits of HNB devices by inhibiting the reduction in biomarkers of exposure. A concern related to this finding is the issue of addiction development itself, and the potential for the normalisation of smoking behaviours using devices that are marketed as 'reduced risk'. ${ }^{40}$

Health risk estimation can be achieved through the linking of individual BoEs to specific health consequences resulting from exposure, to inform on the relative risk of different tobacco products. Both $\mathrm{COHb}$ and 2-AN had the greatest reductions in exposure between HNB devices and conventional cigarettes. $\mathrm{COHb}$ levels are elevated several times above normal in tobacco smokers, ${ }^{41}$ with the resulting displacement of oxygen from hemoglobin leading to headaches, dizziness, and gastrointestinal upset, but also increasing the risk of atherosclerosis. ${ }^{42,43}$ Similarly, 2-AN and 4-ABP are known carcinogens suspected to contribute to bladder cancer). ${ }^{44,45}$ Replacement of conventional cigarettes with a HNB device may therefore confer some level of protection against these health consequences that are often attributed to smoking. However, NNN and NNAL were elevated in comparison to abstinence, and are linked to respiratory and pancreatic cancers, signifying continued safety concerns. ${ }^{45,46}$ Quantifying measurable outcomes such as BoEs contribute to the goal of assessing relative safety, and allow substantiation of claims for reduced potential for harm of HNB devices. To date, two small independent studies have evaluated comparative levels of a single BoE (carbon monoxide) between IQOS, glo, and e-cigarettes, and reported finding no or minimal differences. ${ }^{47,48}$ 
Based on the findings of the current study, further research is required to understand to what degree these 'potential modified risk tobacco products' differ in their delivery of nicotine and HPHCs, and the resulting levels of key BoEs in smokers and close-contact non-smokers. This includes the potential for second-hand smoke from HNB devices to raise BoE levels in nonsmokers. Transparent and standardised independent research utilising clear protocols is required, to allow the comparison and interpretation of multiple, large datasets relating to the safety of these emerging tobacco products. Similar recommendations were made recently by Hendlin et al. (2019) in a systematic review of financial conflicts of interest and harm reduction. ${ }^{49}$ Post-marketing surveillance of the spread and uptake of HNB devices is also needed to identify key population groups exposed to these devices such as adolescents, who may have altered pharmacokinetic profiles for HPHCs compared to the adult participants in this review. Adverse event data was also minimal in these studies due to the short duration of exposure, and long-term safety data would need to include comparative adverse event profiles between HNB and conventional tobacco products.

\section{Limitations}

There are limitations within this review as well as the eligible studies to consider when interpreting and applying these findings. Most notable is the involvement of the tobacco industry in the each of the studies included in this review, with author affiliations and funding issues introducing concerns relating to reporting bias. ${ }^{50-52}$ An additional consideration is that most studies had a short duration of exposure to the intervention materials. Confinement studies such as these are more informative and reliable than ambulatory studies, through having more control on participant exposure, though prevent an assessment of the long-term effects of HNB devices on BoEs. Confinement may have also affected participants' urge to smoke through a reduction in their normal environmental cues, affecting the generalisability of these results to real-world conditions, and an overstatement of the potential health benefits of HNB devices. 
In addition, there was a limited range of BoEs analysed due to inconsistency in the reporting of BoEs within the individual studies, preventing a more complete estimation of comparative levels of harm between HNBs and conventional cigarettes. Most of the studies were conducted in either Poland or Japan, which may confound the results due to metabolic differences between these populations and those from other countries and ethnicities. Precursor products in this review were in some cases not marketed, and with further development led to reductions in toxicant exposure and an underestimation of their total comparative safety to conventional cigarettes. Finally, the moderate quality of the studies identified through the quality appraisal tool (largely related to the unavoidable lack of blinding) requires that the results be interpreted and applied with caution.

\section{CONCLUSIONS}

Heat-not-burn devices such as 'IQOS' and 'glo' are marketed as 'reduced risk' tobacco products, and are claimed to reduce harm to smokers compared to conventional cigarettes. This review supports these claims, with all 12 BoEs that were analysed being significantly lower in the HNB participants compared to those using conventional cigarettes. These BoE reductions were greatest for several known carcinogens, including $\mathrm{COHb}, 2-\mathrm{AN}, 4-\mathrm{ABP}$, and CEMA, indicating the potential for significantly reduced harm when using HNB devices in comparison to conventional cigarettes. In addition, levels of 8 of the 12 BoEs were statistically equivalent between the HNB and abstinence participants, though the levels of some carcinogenic BoEs were significantly increased. HNB devices therefore may have a role in harm reduction though should not be considered as wholly safe. The strong involvement of tobacco manufacturers in these studies demonstrates the need for caution in interpreting these findings, and the need for independent research to be conducted to either confirm or refute these findings. 


\section{FUNDING}

This research did not receive any specific grant from funding agencies in the public, commercial, or not-for-profit sectors.

\section{COMPETING INTERESTS}

The authors declare no competing interests.

\section{ACKNOWLEDGEMENTS}

The authors would like to thank Professor Billie Bonevski from the University of Newcastle for her comments and feedback on the draft manuscript, and for providing recommendations for improvement.

\section{ETHICS}

Not applicable. 


\section{REFERENCES}

1. WHO report on the global tobacco epidemic, 2017: monitoring tobacco use and prevention policies. Geneva: World Health Organization; 2017. Licence: CC BY-NCSA 3.0 IGO.

2. Doll R, Peto R, Boreham J, et al. Mortality in relation to smoking: 50 years' observations on male British doctors. BMJ 2004;328(7455):1519. https://doi.org/10.1136/bmj.38142.554479.AE

3. Lerman C, Caporaso NE, Audrain J, et al. Evidence suggesting the role of specific genetic factors in cigarette smoking. Health Psychol 1999;18(1):14-20

4. Strand BH, Mishra G, Kuh D, et al. Smoking history and physical performance in midlife: results from the British 1946 birth cohort. J Gerontol A Biol Sci Med Sci 2010;66(1):142-149. https://doi.org/10.1093/gerona/glq199

5. Mackay J, Eriksen M, WHO (World Health Organization). The tobacco Atlas. Geneva: World Health Organization; 2002. Accessed $3^{\text {rd }}$ September 2018. Available from: http://www.who.int/tobacco/resources/publications/tobacco_atlas/en/

6. World Health Organization. WHO Framework Convention on Tobacco Control. Geneva: World Health Organization, 2003. Accessed $8^{\text {th }}$ September 2018. Available from: http://apps. who.int/iris/bitstream/10665/42811/1/9241591013.pdf?ua=1

7. Pollay RW. Targeting youth and concerned smokers: evidence from Canadian tobacco industry documents. Tob Control 2000;9:136-147.

http://dx.doi.org/10.1136/tc.9.2.136

8. Wakefield M, Morley C, Horan JK, et al. The cigarette pack as image: new evidence from tobacco industry documents. Tob Control 2002;11(Suppl1):i73-80. http://dx.doi.org/10.1136/tc.11.suppl_1.i73

9. Perry CL. The tobacco industry and underage youth smoking: tobacco industry documents from the Minnesota Litigation. Arch Pediatr Adolesc Med 1999;153(9):935-941. http://dx.doi.org/10.1001/archpedi.153.9.935

10. Hastings G, MacFadyen L. A day in the life of an advertising man: review of internal documents from the UK tobacco industry's principal advertising agencies. BMJ 2000;321:366-371. https://doi.org/10.1136/bmj.321.7257.366

11. Philip Morris: Heated Tobacco Products. https://www.pmi.com/science-andinnovation/heated-tobacco-products. Accessed 3rd September 2018.

12. Breland AB, Kleykamp BA, Eissenberg T. Clinical laboratory evaluation of potential reduced exposure products for smokers. Nicotine Tob Res 2006;8(6):727-738. https://doi.org/10.1080/14622200600789585

13. Haig, Matt. Brand Failures: The Truth about the 100 Biggest Branding Mistakes of All Time. 2003. Kogan Page Publishers.

14. Murguía SJ. Epic Fails: The Edsel, the Mullet, and Other Icons of Unpopular Culture. 2018. Rowman \& Littlefield.

15. Caputi TL. Industry watch: heat-not-burn tobacco products are about to reach their boiling point. Tob Control 2017;26(5):609-610. http://dx.doi.org/10.1136/tobaccocontrol-2016-053264

16. Institute of Medicine. Clearing the Smoke: Assessing the Science Base for Tobacco Harm Reduction. 2001. National Academy Press, Washington, DC. http://www.nationalacademies.org/hmd/Reports/2001/Clearing-the-Smoke-TheScience-Base-for-Tobacco-Harm-Reduction.aspx

17. McNeill A, Munafò MR. Reducing harm from tobacco use. J Psychopharmacol 2013;27(1):13-18. https://doi.org/10.1177\%2F0269881112458731 
18. Simonavicius E, McNeill A, Shahab L, et al. Heat-not-burn tobacco products: a systematic literature review. Tob Control Published online first $4^{\text {th }}$ September 2018. http://dx.doi.org/10.1136/tobaccocontrol-2018-054419

19. Popova L, Lempert LK, Glantz SA. Light and mild redux: heated tobacco products' reduced exposure claims are likely to be misunderstood as reduced risk claims. Tob Control Published online first $12^{\text {th }}$ September 2018. http://dx.doi.org/10.1136/tobaccocontrol-2018-054324

20. Caputi TL, Leas E, Dredze M, et al. They're heating up: Internet search query trends reveal significant public interest in heat-not-burn tobacco products. PLoS One 2017;12(10):e0185735. https://doi.org/10.1371/journal.pone.0185735

21. Moher D, Liberati A, Tetzlaff J, et al. Preferred reporting items for systematic reviews and meta-analyses: the PRISMA statement. Ann Intern Med 2009;151(4):264-9. https://doi.org/10.7326/0003-4819-151-4-200908180-00135

22. Tufanaru C, Munn Z, Aromataris E, et al. Chapter 3: Systematic reviews of effectiveness. In: Aromataris E, Munn Z (Editors). Joanna Briggs Institute Reviewer's Manual. The Joanna Briggs Institute, 2017. Available from https://reviewersmanual.joannabriggs.org/

23. Carlson KD, Schmidt FL. Impact of experimental design on effect size: Findings from the research literature on training. J Appl Psychol 1999;84(6):851.

24. Hedges LV. Distribution theory for Glass's estimator of effect size and related estimators. J Educ Stat 1981;6(2):107-128. https://doi.org/10.3102\%2F10769986006002107

25. Morris SB. Estimating effect sizes from pretest-posttest-control group designs. Organ Res Methods 2008;11(2):364-386. https://doi.org/10.1177\%2F1094428106291059

26. DerSimonian R, Laird N. Meta-analysis in clinical trials. Control Clin Trials 1986;7(3):177-88. https://doi.org/10.1016/0197-2456(86)90046-2

27. Sakaguchi C, Kakehi A, Minami N, et al. Exposure evaluation of adult male Japanese smokers switched to a heated cigarette in a controlled clinical setting. Regul Toxicol Pharmacol 2014;69(3):338-347. https://doi.org/10.1016/j.yrtph.2014.04.016

28. Haziza C, de La Bourdonnaye G, Merlet S, et al. Assessment of the reduction in levels of exposure to harmful and potentially harmful constituents in Japanese subjects using a novel tobacco heating system compared with conventional cigarettes and smoking abstinence: a randomized controlled study in confinement. Regul Toxicol Pharmacol 2016;81:489-499. https://doi.org/10.1016/j.yrtph.2016.09.014

29. Haziza C, de La Bourdonnaye G, Skiada D, et al. Evaluation of the tobacco heating system 2.2. Part 8: 5-day randomized reduced exposure clinical study in Poland. Regul Toxicol Pharmacol 2016;81(Suppl2):S139-150. https://doi.org/10.1016/j.yrtph.2016.11.003

30. Lüdicke F, Haziza C, Weitkunat R, et al. Evaluation of biomarkers of exposure in smokers switching to a carbon-heated tobacco product: a controlled, randomized, open-label 5-day exposure study. Nicotine Tob Res 2016;18(7):1606-13. https://doi.org/10.1093/ntr/ntw022

31. Lüdicke F, Baker G, Magnette J, et al. Reduced exposure to harmful and potentially harmful smoke constituents with the tobacco heating system 2.1. Nicotine Tob Res 2016;19(2):168-75. https://doi.org/10.1093/ntr/ntw164

32. Gale N, McEwan M, Eldridge AC, et al. Changes in Biomarkers of Exposure on Switching from a Conventional Cigarette to Tobacco Heating Products: A Randomized, Controlled Study in Healthy Japanese Subjects. Nicotine Tob Res Published online $15^{\text {th }}$ June 2018. https://doi.org/10.1093/ntr/nty104 
33. Lüdicke F, Picavet P, Baker G, et al. Effects of Switching to the Tobacco Heating System 2.2 Menthol, smoking abstinence, or continued cigarette smoking on biomarkers of exposure: A randomized, controlled, open-label, multicenter study in sequential confinement and ambulatory settings (part 1). Nicotine Tob Res 2017;20(2):161-172. https://doi.org/10.1093/ntr/ntw287

34. Yuki D, Takeshige Y, Nakaya K, et al. Assessment of the exposure to harmful and potentially harmful constituents in healthy Japanese smokers using a novel tobacco vapor product compared with conventional cigarettes and smoking abstinence. Regul Toxicol Pharmacol 2018;96:127-134. https://doi.org/10.1016/j.yrtph.2018.05.001

35. Haziza C, De La Bourdonnaye G, Donelli A, et al. Reduction in Exposure to Selected Harmful and Potentially Harmful Constituents Approaching Those Observed Upon Smoking Abstinence in Smokers Switching to the Menthol Tobacco Heating System 2.2 for 3 Months (Part 1). Nicotine Tob Res 2019, ntz013. https://doi.org/10.1093/ntr/ntz013

36. Lüdicke F, Ansari SM, Lama N, et al. Effects of Switching to a Heat-Not-Burn Tobacco Product on Biologically-Relevant Biomarkers to assess a Candidate Modified Risk Tobacco Product: A Randomized Trial. Cancer Epidemiol Biomarkers Prev 2019, cebp-0915. https://doi.org/10.1158/1055-9965.EPI-18-0915

37. Haziza C, de La Bourdonnaye G, Skiada D, et al. Biomarker of exposure level data set in smokers switching from conventional cigarettes to Tobacco Heating System 2.2, continuing smoking or abstaining from smoking for 5 days. Data Brief 2017;10:283-293. https://doi.org/10.1016/j.dib.2016.11.047

38. Murphy J, Gaca M, Lowe F, et al. Assessing modified risk tobacco and nicotine products: description of the scientific framework and assessment of a closed modular electronic cigarette. Regul Toxicol Pharmacol 2017;90:342-357. https://doi.org/10.1016/j.yrtph.2017.09.008

39. Wills TA, Knight R, Williams RJ, et al. Risk factors for exclusive e-cigarette use and dual e-cigarette use and tobacco use in adolescents. Pediatrics 2015;135(1):e43-51. https://doi.org/10.1542/peds.2014-0760

40. Measham F, O’Brien K, Turnbull G. "Skittles \& Red Bull is my favourite flavour": Ecigarettes, smoking, vaping and the changing landscape of nicotine consumption amongst British teenagers-implications for the normalisation debate. Drugs 2016;23(3):224-237. https://doi.org/10.1080/09687637.2016.1178708

41. Turner J, Sillett R, McNicol M. Effect of cigar smoking on carboxyhaemoglobin and plasma nicotine concentrations in primary pipe and cigar smokers and ex-cigarette smokers. Br Med J 1977;2(6099):1387-1389. https://dx.doi.org/10.1136\%2Fbmj.2.6099.1387

42. Fawcett TA, Moon RE, Fracica PJ, et al. Warehouse workers' headache. Carbon monoxide poisoning from propane-fueled forklifts. J Occup Med. 1992;34(1):12-15.

43. Allred EN, Bleecker ER, Chaitman BR, et al. Short-term effects of carbon monoxide exposure on the exercise performance of subjects with coronary artery disease. $N$ Engl J Med 1989 23;321(21):1426-32. https://doi.org/10.1056/NEJM198911233212102

44. Centers for Disease Control and Prevention. NIOSH pocket guide to chemical hazards: beta-Naphthylamine. https://www.cdc.gov/niosh/npg/npgd0442.html. Page last updated 29 $9^{\text {th }}$ November 2018, last accessed $25^{\text {th }}$ May 2019.

45. US Department of Health and Human Services National Toxicology Program. $14^{\text {th }}$ Report on Carcinogens, 2016. https://ntp.niehs.nih.gov/ntp/roc/content/profiles/aminobiphenyl.pdf

46. US Department of Human and Health Services National Toxicology Program. Final report on carcinogens background document for environmental tobacco smoke, 1998. 
https://ntp.niehs.nih.gov/ntp/newhomeroc/other_background/environmentalts_noapps 508.pdf

47. Caponnetto P, Maglia M, Prosperini G, et al. Carbon monoxide levels after inhalation from new generation heated tobacco products. Respir Res 2018;19(1):164. https://doi.org/10.1186/s12931-018-0867-z

48. Adriaens K, Gucht DV, Baeyens F. IQOSTM vs. e-Cigarette vs. Tobacco Cigarette: A Direct Comparison of Short-Term Effects after Overnight-Abstinence. Int J Environ Res Public Health 2018;15(12):2902. https://doi.org/10.3390/ijerph15122902

49. Hendlin YH, Vora M, Elias J, Ling PM. Financial conflicts of interest and stance on tobacco harm reduction: a systematic review. Am J Pub Health 2019; e1-e8

50. Lasseter T, Bansal P, Wilson T, et al. Special report: scientists describe problems in Philip Morris e-cigarette experiments. Reuters. December 20, 2017. Last accessed $30^{\text {th }}$ January 2019. https://www.reuters.com/article/us-tobacco-iqos-sciencespecialreport/special-report-scientists-describe-problems-in-philip-morris-e-cigaretteexperiments-idUSKBN1EE1GG?utm_source=applenews

51. Elias J, Dutra LM, Helen GS, et al. Revolution or redux? assessing IQOS through a precursor product. Tob Control 2018;27(Suppl1):s102-110. http://dx.doi.org/10.1136/tobaccocontrol-2018-054327

52. Helen GS, Jacob III P, Nardone N, et al. IQOS: examination of Philip Morris International's claim of reduced exposure. Tob Control 2018;27(Suppl1):s30-36. http://dx.doi.org/10.1136/tobaccocontrol-2018-054321 

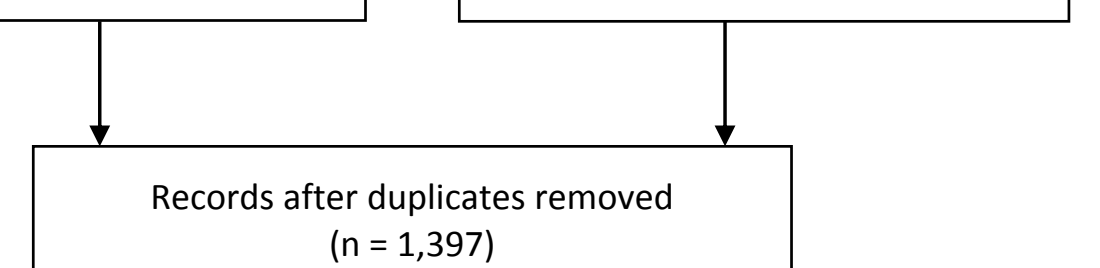

$$
(n=1,397)
$$

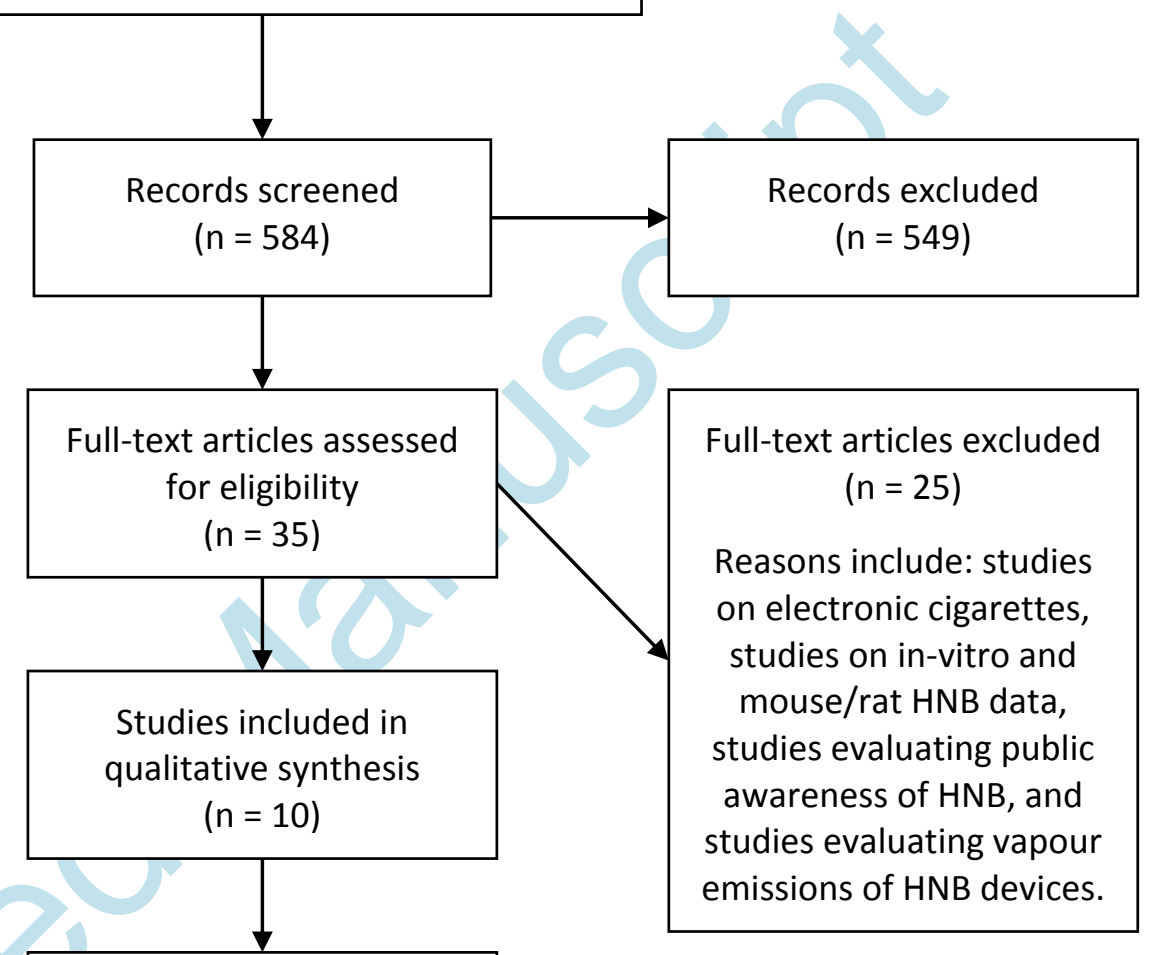

Studies included in quantitative synthesis

(meta-analysis)

$$
(n=10)
$$

Figure 1. Flowchart of the systematic search strategy. 


\section{2-AN: HNB vs. Conventional}

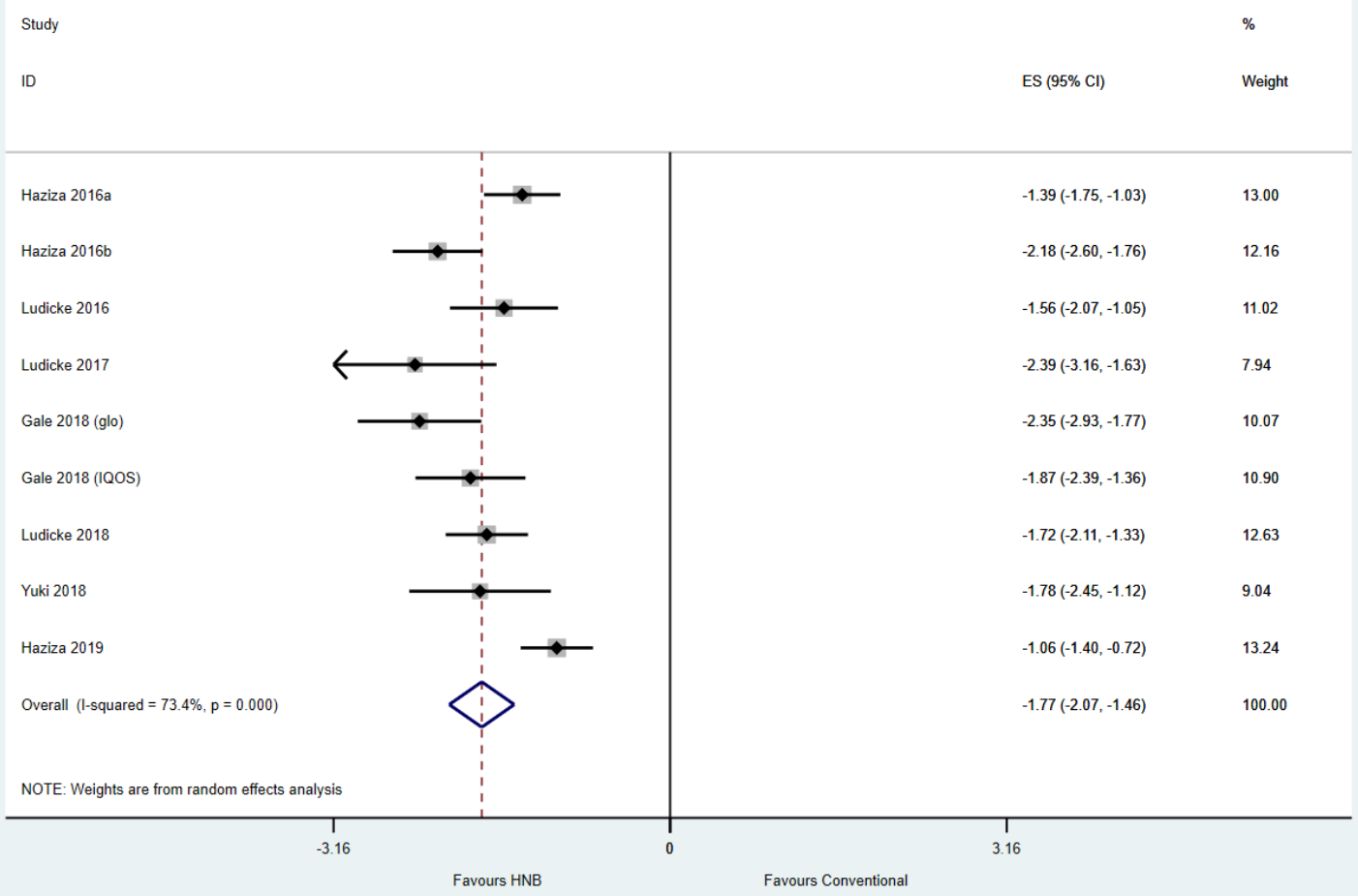

Figure 2. The forest plot illustrating the post-exposure mean differences in 2-AN between HNB and CC. 
Table 1. Characteristics of the studies eligible for inclusion in this meta-analysis $(n=10)$.

\begin{tabular}{|c|c|c|c|c|c|c|c|c|c|}
\hline Study & $\begin{array}{c}\text { Locatio } \\
n \\
\text { (Funde } \\
\mathbf{r}^{\&} \text { ) and } \\
\text { JBI } \\
\text { Score }^{\#}\end{array}$ & $\begin{array}{l}\text { Intervent } \\
\quad \text { ion } \\
\text { Period \& } \\
\text { Setting }\end{array}$ & $\begin{array}{l}\text { Total* } \\
\text { Particip } \\
\text { ants }\end{array}$ & $\begin{array}{l}\text { No. of } \\
\text { Male: } \\
\text { Femal } \\
\mathrm{e}^{*}\end{array}$ & $\begin{array}{c}\text { Age } \\
\text { Ran } \\
\text { ge } \\
\text { (yea } \\
\text { rs) }\end{array}$ & $\begin{array}{c}\text { Smoki } \\
\text { ng } \\
\text { Habit } \\
\text { s }\end{array}$ & $\begin{array}{c}\text { Conventi } \\
\text { onal } \\
\text { Cigarette } \\
\text { Participa } \\
\text { nt \# }\end{array}$ & $\begin{array}{c}\text { Interven } \\
\text { tion } \\
\text { Participa } \\
\text { nt \# }\end{array}$ & $\begin{array}{l}\text { Abstine } \\
\text { nt } \\
\text { Particip } \\
\text { ant \# }\end{array}$ \\
\hline $\begin{array}{c}\text { Sakagu } \\
\text { chi } \\
2014^{27}\end{array}$ & $\begin{array}{c}\text { Japan } \\
\text { (JTI) } \\
8\end{array}$ & $\begin{array}{c}28 \text { days } \\
\text { (ambulato } \\
\text { ry) }\end{array}$ & 69 & $69: 0$ & $\begin{array}{c}21- \\
49\end{array}$ & $\begin{array}{c}\geq 20 \\
\text { CPD } \\
\text { for }> \\
12 \\
\text { month } \\
\quad \mathrm{s} \\
\end{array}$ & 23 & $\begin{array}{c}46 \\
\text { (precurso } \\
\text { r) }\end{array}$ & - \\
\hline $\begin{array}{c}\text { Haziza } \\
2016 a^{28}\end{array}$ & $\begin{array}{c}\text { Japan } \\
\text { (PMI) } \\
8\end{array}$ & $\begin{array}{c}5 \text { days } \\
\text { (confinem } \\
\text { ent) }\end{array}$ & 158 & $\begin{array}{c}80: \\
80\end{array}$ & $\begin{array}{c}23- \\
65\end{array}$ & $\begin{array}{c}\geq 10 \\
\text { CPD } \\
\text { for }>3 \\
\text { years }\end{array}$ & 40 & $\begin{array}{c}80 \\
\text { (IQOS) }\end{array}$ & 38 \\
\hline $\begin{array}{c}\text { Haziza } \\
2016 b^{29} \\
\wedge\end{array}$ & $\begin{array}{c}\text { Poland } \\
\text { (PMI) } \\
9\end{array}$ & $\begin{array}{c}5 \text { days } \\
\text { (confinem } \\
\text { ent) }\end{array}$ & 159 & $\begin{array}{c}80: \\
79\end{array}$ & $\begin{array}{c}21- \\
65\end{array}$ & $\begin{array}{c}\geq 10 \\
\text { CPD } \\
\text { for }>3 \\
\text { years }\end{array}$ & 41 & $\begin{array}{c}79 \\
\text { (IQOS) }\end{array}$ & 39 \\
\hline $\begin{array}{c}\text { Lüdick } \\
\text { e } \\
2016^{30}\end{array}$ & $\begin{array}{c}\text { Poland } \\
\text { (PMI) } \\
9\end{array}$ & $\begin{array}{c}5 \text { days } \\
\text { (confinem } \\
\text { ent) }\end{array}$ & 112 & $\begin{array}{c}56: \\
56\end{array}$ & $\begin{array}{c}23- \\
55\end{array}$ & $\begin{array}{l}\geq 10 \\
\text { CPD } \\
\text { for }>5 \\
\text { years }\end{array}$ & 28 & $\begin{array}{c}56 \\
\text { (precurso } \\
\text { r) }\end{array}$ & 28 \\
\hline $\begin{array}{c}\text { Lüdick } \\
\mathbf{e} \\
2017^{31}\end{array}$ & $\begin{array}{c}\text { Poland } \\
\text { (PMI) } \\
9\end{array}$ & $\begin{array}{c}5 \text { days } \\
\text { (confinem } \\
\text { ent) }\end{array}$ & 40 & $\begin{array}{l}19: \\
23\end{array}$ & $\begin{array}{c}23- \\
65\end{array}$ & $\begin{array}{c}\geq 10 \\
\text { CPD } \\
\text { for }>3 \\
\text { years }\end{array}$ & 20 & $\begin{array}{c}20 \\
\text { (precurso } \\
\text { r) }\end{array}$ & - \\
\hline $\begin{array}{c}\text { Gale } \\
2018^{32}\end{array}$ & $\begin{array}{c}\text { Japan } \\
\text { (BAT) } \\
9\end{array}$ & $\begin{array}{c}5 \text { days } \\
\text { (confinem } \\
\text { ent) }\end{array}$ & 180 & $\begin{array}{c}90: \\
90\end{array}$ & $\begin{array}{c}23- \\
55\end{array}$ & $\begin{array}{c}\geq 10 \\
\text { CPD } \\
\text { for }>3 \\
\text { years }\end{array}$ & 60 & $\begin{array}{c}60 \text { (glo) } \\
30 \\
(\mathrm{IQOS})\end{array}$ & 30 \\
\hline $\begin{array}{c}\text { Lüdick } \\
\text { e } \\
2018^{33}\end{array}$ & $\begin{array}{c}\text { Japan } \\
(\mathrm{PMI}) \\
9\end{array}$ & $\begin{array}{c}5 \text { days } \\
\text { (confinem } \\
\text { ent) } \\
85 \text { days } \\
\text { (ambulato } \\
\text { ry) } \\
\end{array}$ & 155 & $\begin{array}{c}92: \\
68\end{array}$ & $\begin{array}{c}23- \\
65\end{array}$ & $\begin{array}{c}\geq 10 \\
\text { CPD } \\
\text { for }>3 \\
\text { years }\end{array}$ & 41 & $\begin{array}{c}76 \\
\text { (precurso } \\
\text { r) }\end{array}$ & 38 \\
\hline $\begin{array}{c}\text { Yuki } \\
2018^{34}\end{array}$ & $\begin{array}{c}\text { Japan } \\
\text { (JTI) } \\
9\end{array}$ & $\begin{array}{c}5 \text { days } \\
\text { (confinem } \\
\text { ent) }\end{array}$ & 60 & $\begin{array}{c}42: \\
18\end{array}$ & $\begin{array}{c}21- \\
65\end{array}$ & $\begin{array}{c}\geq 11 \\
\text { CPD } \\
\text { for }> \\
12 \\
\text { month } \\
\quad \mathrm{s} \\
\end{array}$ & 20 & $\begin{array}{c}20 \\
\text { (precurso } \\
\text { r) }\end{array}$ & 20 \\
\hline $\begin{array}{c}\text { Haziza } \\
2019^{35}\end{array}$ & $\begin{array}{c}\text { USA } \\
(\mathrm{PMI}) \\
9\end{array}$ & $\begin{array}{c}5 \text { days } \\
\text { (confinem } \\
\text { ent) } \\
85 \text { days } \\
\text { (ambulato } \\
\text { ry) }\end{array}$ & 160 & $\begin{array}{c}96: \\
64\end{array}$ & $\begin{array}{c}22- \\
66\end{array}$ & $\begin{array}{c}\geq 10 \\
\text { CPD } \\
\text { for }>3 \\
\text { years }\end{array}$ & 41 & $\begin{array}{c}80 \\
\text { (IQOS) }\end{array}$ & 39 \\
\hline $\begin{array}{c}\text { Lüdick } \\
\text { e } \\
2019^{36}\end{array}$ & $\begin{array}{c}\text { USA } \\
(\mathrm{PMI}) \\
9\end{array}$ & $\begin{array}{c}6 \text { months } \\
\text { (ambulato } \\
\text { ry) }\end{array}$ & 673 & $\begin{array}{c}397: \\
276\end{array}$ & $30-$ & $\begin{array}{c}\geq 10 \\
\text { CPD } \\
\text { for }> \\
10 \\
\text { years }\end{array}$ & 428 & $\begin{array}{c}245 \\
\text { (IQOS) }\end{array}$ & - \\
\hline
\end{tabular}

* Total number of participants completing the study, and the number of participants assigned to the intervention groups before drop-out 
\& JTI: Japan Tobacco Inc., PMI: Philip Morris International, BAT: British American Tobacco

\# JBI: Joanna Briggs Institute quality checklist, which had a maximum score of 13 CPD: Cigarettes Per Day

$\wedge$ Haziza 2016b published a second article including data relating to this study ${ }^{37}$ 
Table 2. BoE effect sizes (standard deviations) and p-values for the HNB group versus conventional cigarette $(\mathrm{CC})$ and Abstinence (Abs) groups.

\begin{tabular}{|c|c|c|c|}
\hline Biomarker of Exposure (BoE) & Comparison & $\begin{array}{l}\text { Effect Size (SD) } \\
\text { and } 95 \% \text { CI }\end{array}$ & p-value \\
\hline \multirow{2}{*}{$\begin{array}{c}\text { 2-aminoaphthalene } \\
(2-A N)\end{array}$} & HNB vs. CC & $-1.77(-2.07,-1.46)$ & $<0.001$ \\
\hline & HNB vs. Abs & $-0.08(-0.26,0.09)$ & 0.367 \\
\hline \multirow{2}{*}{$\begin{array}{c}\text { Carboxyhemoglobin } \\
\text { (CoHB) }\end{array}$} & HNB vs. CC & $-1.72(-2.48,-0.97)$ & $<0.001$ \\
\hline & HNB vs. Abs & $0.14(-0.08,0.37)$ & 0.213 \\
\hline \multirow{2}{*}{$\begin{array}{c}\text { 4-aminobiphenyl } \\
\text { (4-ABP) }\end{array}$} & HNB vs. CC & $-1.53(-1.76,-1.30)$ & $<0.001$ \\
\hline & HNB vs. Abs & $-0.04(-0.22,0.13)$ & 0.639 \\
\hline \multirow{2}{*}{$\begin{array}{c}\text { 2-cyanoethylmercapturic acid } \\
\text { (CEMA) }\end{array}$} & HNB vs. CC & $-1.38(-1.79,-0.98)$ & $<0.001$ \\
\hline & HNB vs. Abs & $-0.04(-0.19,0.11)$ & 0.640 \\
\hline \multirow{2}{*}{$\begin{array}{c}\text { 3-hydroxypropylmercaptapuric acid } \\
\text { (3-HPMA) }\end{array}$} & HNB vs. $\mathrm{CC}$ & $-1.22(-1.63,-0.82)$ & $<0.001$ \\
\hline & HNB vs. Abs & $0.21(0.02,0.40)$ & 0.027 \\
\hline \multirow{2}{*}{$\begin{array}{c}\text { 1-hydroxypyrene } \\
\text { (1-OHP) }\end{array}$} & HNB vs. CC & $-1.17(-1.53,-0.80)$ & $<0.001$ \\
\hline & HNB vs. Abs & $-0.08(-0.21,0.05)$ & 0.233 \\
\hline \multirow{2}{*}{$\begin{array}{l}\text { S-phenylmercapturic acid } \\
\text { (S-PMA) }\end{array}$} & HNB vs. CC & $-1.14(-1.35,-0.94)$ & $<0.001$ \\
\hline & HNB vs. Abs & $-0.10(-0.28,0.08)$ & 0.275 \\
\hline \multirow{2}{*}{$\begin{array}{c}\text { o-toluidine } \\
\text { (o-tol) }\end{array}$} & HNB vs. CC & $-1.03(-1.25,-0.80)$ & $<0.001$ \\
\hline & HNB vs. Abs & $-0.00(-0.16,0.16)$ & 0.988 \\
\hline \multirow{2}{*}{$\begin{array}{c}\text { monohydroxybutenyl-mercapturic } \\
\text { acid (MHBMA) }\end{array}$} & HNB vs. CC & $-0.93(-1.21,-0.66)$ & $<0.001$ \\
\hline & HNB vs. Abs & $-0.14(-0.35,0.07)$ & 0.192 \\
\hline \multirow{2}{*}{$\begin{array}{c}\text { N-nitrosonornicotine } \\
(\mathrm{NNN})\end{array}$} & HNB vs. CC & $-0.82(-1.15,-0.48)$ & $<0.001$ \\
\hline & HNB vs. Abs & $0.22(0.01,0.43)$ & 0.041 \\
\hline \multirow{2}{*}{$\begin{array}{l}\text { 4-(methylnitrosamino)-1-(3-pyridyl)- } \\
\text { 1-butanol (NNAL) }\end{array}$} & HNB vs. CC & $-0.65(-0.82,-0.48)$ & $<0.001$ \\
\hline & HNB vs. Abs & $0.11(0.03,0.18)$ & 0.005 \\
\hline \multirow{2}{*}{$\begin{array}{c}\text { Total Nicotine Equivalents } \\
\text { (TNeq) }\end{array}$} & HNB vs. CC & $-0.37(-0.70,-0.05)$ & 0.023 \\
\hline & HNB vs. Abs & $1.91(1.40,2.41)$ & $<0.001$ \\
\hline
\end{tabular}

